\title{
The Correlation between Helicobacter Pylori Infection and Disease Severity in Patients with Systemic Sclerosis
}

\author{
Elham Atabati ${ }^{1}$, Zhaleh Shariati Sarabi ${ }^{2}$, Mohammad Hasan Jokar ${ }^{3}$, Kamila Hashemzadeh ${ }^{2}$, \\ Zahra Mirfeizi ${ }^{2, *}$
}

1. Clinical Research Development Unit, Valiasr Hospital, Birjand University of Medical Sciences, Birjand, Iran

2. Rheumatic Diseases Research Center, Mashhad University of Medical Sciences, Mashhad, Iran

3. Department of Internal Medicine, Imam Reza Hospital, Mashhad University of Medical Sciences, Mashhad, Iran

* Corresponding Author:

Zahra Mirfeizi, MD

Rheumatic Diseases Research Center, Mashhad University of Medical Sciences,

Mashhad, Iran

Postal code: $99199-91799$

Telefax: + 985632041364

Email: Mirfeiziz@mums.ac.ir

Received: 14 Nov. 2020

Accepted: 10 Jun. 2021

\section{ABSTRACT}

\section{BACKGROUND}

Systemic sclerosis ( $\mathrm{SSc}$ ) is a relatively common connective tissue disease, which is characterized by inflammation, progressive skin fibrosis, and injuries of small vessels, particularly in the lung and kidney. It seems that Helicobacter pylori (H. pylori) might contribute to the development of SSc as an extra-gastrointestinal autoimmune disease. We investigated the association between $H$. pylori infections and disease severity in patients with SSc.

\section{METHODS}

This is a cross-sectional study. Sampling method in this study was census method in such a way that all patients with SSc referred to Imam Reza Education and Research University Medical Center from May 2015 to August 2016 were included in the study. Finally, 74 patients were selected based on the inclusion criteria.

Inclusion criteria were: 1. Definitive SSc based on American College of Rheumatology/ European League Against Rheumatism 2010 (ACR/EULAR) classification for scleroderma, which was diagnosed within the last two years. 2 . Not taking any proton pump inhibitors. 3. Not taking any H. pylori treatment with a standard regimen within the recent 2 months.

Disease severity was assessed and determined by two rheumatologists based on the Medsger's Disease Severity Scale (MDSS). H. pylori stool antigen was evaluated based on the test which sensitivity and specificity was proven. All obtained data were statistically analyzed by SPSS 16 using Fisher's exact test Spearman correlation test (RSpearman).

\section{RESULTS}

Forty one (55.4\%) of the 74 patients had positive stool antigens. We found a significant positive association between the severity of disease based on MDSS and titer of $H$. pylori stool antigen $(p \leq 0.001)$.

\section{CONCLUSION}

This study reveals that $H$. pylori infection may play a significant role in the severity of organ involvement in SSc.

\section{KEYWORDS:}

Systemic sclerosis, Helicobacter pylori, Severity of disease, cytotoxic drugs

Please cite this paper as:

Atabati E, Shariati Sarabi Z, Jokar MH, Hashemzadeh K, Mirfeizi Z. The Correlation between Helicobacter Pylori Infection and Disease Severity in Patients with Systemic Sclerosis. Middle East J Dig Dis 2021;13:253-258. doi: 10.34172/mejdd.2021.232. 


\section{INTRODUCTION}

Systemic sclerosis (SSc) is a connective tissue disease. Through autoimmune responses, it causes inflammation, progressive skin fibrosis, and small vessel occlusion as a result of excessive deposition of collagen. It is distinguished from scleroderma as it involves several organs, including the lung, heart, gastrointestinal tract, musculoskeletal system, and kidney. ${ }^{1,2}$ Diagnostic findings in SSc comprise skin hardness and/or thickening of the hands and fingers, telangiectasia, fingertip lesions, nail fold capillary abnormalities, Raynaud's phenomenon, and autoimmune antibodies. ${ }^{3}$ Given the multiple complications and the nature of SSc, the patients require constant visits and follow-up because over half of the patients fail to survive as a result of the direct complication(s) of the disease. In addition to the high mortality rate due to internal organ involvement, SSc leads to organ dysfunction, reduced quality of life, and a wide range of severe disabilities. ${ }^{4}$ Viruses, genetic factors, medications, and the surrounding environment are among contributors to SSc development. ${ }^{5}$ The associations between SSc and infectious agents have been discussed in the past 25 years. ${ }^{6}$ Previous studies have reported that improvement of skin, muscle, peripheral vascular organs manifestation, and laboratory findings as well as disease activity and severity happen after eradication of H. pylori in patients with SSc. ${ }^{7}$ Accordingly, it seems that $H$. pylori as a gram-negative bacillus colonizing the gastric mucosa may contribute to the development and intensification of several autoimmune diseases, including sclerosis. ${ }^{7}$ This issue subsequently raises the hypothesis of possible connections between SSc severity and $H$. pylori infection. Hence, in the present study, we investigated the correlation between $H$. pylori infection and disease severity in patients with SSc. The aim of this study was to evaluate the role of infection with $H$. pylori bacillus in disease development and exacerbation of the symptoms in patients with scleroderma.

\section{MATERIALS AND METHODS}

In this cross-sectional study, sampling method in this study was census method in such a way that all patients with SSc referred to Imam Reza Education and Research University Medical Center from May 2015 to August 2016 were included in the study. Finally, 74 patients were selected based on the inclusion criteria.

\section{Inclusion Criteria were}

1. Definitive SSc based on ACR/EULAR 2010 classification for scleroderma, which was diagnosed within the last two years.

2. Not taking any proton pump inhibitors.

3. Even not taking any $H$. pylori treatment with a standard regimen within the recent 2 months. Medical history taking and thorough physical examinations were done by two rheumatologists for skin thickening, gastrointestinal and respiratory symptoms, and Raynaud's phenomenon on the basis of Medsger's Disease Severity Scale $^{8}$ (table 1) with a special focus on SSc. Highresolution computed tomography (CT), echocardiography, respiratory function test, barium swallow, or endoscopy were performed at the beginning of the study or within six months prior to it. Moreover, stool samples were taken in order to check for free $H$. pylori stool antigen.

Medsger's scoring method was used to assess disease severity. In this method, each organ is evaluated according to the patients' history, physical examination, and laboratory measures, whereby the disease symptoms are categorized into five groups representing $0=$ normal, $1=$ mild, $2=$ moderate, $3=$ severe, and $4=$ end-stage. The stool antigen test (Hp Ag) was performed by ELISA technique using monoclonal antibody kits of Acon Abacus Company. The antigen titer was quantified with antigen levels where levels lower than 45 micrograms per milliliter were considered negative, and levels over 45 were considered positive.

At the beginning of the study, all the patients were presented with a summary of the study goals in simple language. If they agreed and signed written informed consent forms, they were enrolled in the study. No cost was incurred on the patients for the implementation of the project. Patients were incorporated based on the physician's diagnosis and patient satisfaction. The ethics code was IR.MUMS.fm.REC.1394.373

Collected data were statistically analyzed by SPSS 16 using Fisher's exact test and Spearman correlation test (RSpearman). The significance level was set at $p=0.05$.

\section{RESULTS}

Of the 74 patients with SSc, 69 were female (93.2\%), and 5 were male $(6.8 \%)$. The mean age of the patients was $42.62 \pm 6.9$ years. A total of 41 patients $(55.4 \%)$ 
Table 1: Medsger's Systemic Sclerosis Severity Scale

\begin{tabular}{|c|c|c|c|c|c|}
\hline $\begin{array}{l}\text { Organ } \\
\text { System }\end{array}$ & 0 (Normal) & 1 (Mild) & 2 (Moderate) & 3 (Server) & 4 (End Stage) \\
\hline General & $\begin{array}{c}\text { WT loss }<5 \% \\
\text { PCV } 37 \% \\
\mathrm{Hb}>2.3 \mathrm{gr} / 1\end{array}$ & $\begin{array}{l}\text { WT loss }=5-9.9 \% \\
\mathrm{PCV}=33-36.9 \% \\
\mathrm{Hb}=11-12.2 \mathrm{gr} / 1\end{array}$ & $\begin{array}{c}\text { WT loss }=10-14.9 \% \\
\mathrm{PCV}=29-32.9 \% \\
\mathrm{Hb}=9.7-10.9 \mathrm{gr} / 1\end{array}$ & $\begin{array}{c}\mathrm{WT}=15-19.9 \% \\
\mathrm{PCV}=25-28.9 \% \\
\mathrm{Hb}=8.3-9.6 \mathrm{gr} / 1\end{array}$ & $\begin{array}{c}\text { WT loss }>20 \% \\
\mathrm{PCV}<25 \% \\
\mathrm{Hb}<8.3 \mathrm{gr} / 1\end{array}$ \\
\hline $\begin{array}{l}\text { Peripheral } \\
\text { vascular }\end{array}$ & $\begin{array}{l}\text { No Raynaud's } \\
\text { Raynaud's not } \\
\text { requiring } \\
\text { vasodilator }\end{array}$ & $\begin{array}{c}\text { Raynaud's Requiring } \\
\text { vasodilator }\end{array}$ & Digital Piling scars & $\begin{array}{l}\text { Digital Tip } \\
\text { ulcerations }\end{array}$ & Digital Gangrene \\
\hline Skin & $\mathrm{TSS}=0$ & $\mathrm{TSS}=1-14$ & $\mathrm{TSS}=15-29$ & $\mathrm{TSS}=30-39$ & $\mathrm{TSS}>40$ \\
\hline Joint/tendon & $\mathrm{FTP}=0-0.9 \mathrm{~cm}$ & $\mathrm{FTP}=1-1.9 \mathrm{~cm}$ & $\mathrm{FTP}=2-3.9 \mathrm{~cm}$ & $\mathrm{FTP}=4-4.9 \mathrm{~cm}$ & $\mathrm{FTP}=5 \mathrm{~cm}$ \\
\hline Muscle & $\begin{array}{c}\text { Normal Proximal } \\
\text { Muscle } \\
\text { Strength }\end{array}$ & $\begin{array}{c}\text { Proximal Weakness } \\
\text { Mild }\end{array}$ & $\begin{array}{c}\text { Proximal Weakness } \\
\text { moderate }\end{array}$ & $\begin{array}{c}\text { Proximal Weakness } \\
\text { server }\end{array}$ & $\begin{array}{l}\text { Ambulation Aids } \\
\text { required }\end{array}$ \\
\hline $\begin{array}{l}\text { Gastro Intesti- } \\
\text { nal tract }\end{array}$ & $\begin{array}{l}\text { Normal Esopha- } \\
\text { gram Normal } \\
\text { bowel series }\end{array}$ & $\begin{array}{c}\text { Distal Esophageal } \\
\text { Hypoperistalsis } \\
\text { Small bowel Series } \\
\text { abnormal }\end{array}$ & $\begin{array}{c}\text { Antibiotic Required } \\
\text { For Bacterial } \\
\text { Overgrowth }\end{array}$ & $\begin{array}{c}\text { Malabsorption } \\
\text { syndrome episodes of } \\
\text { pseudo-obstruction }\end{array}$ & $\begin{array}{c}\text { Hyper alimentation } \\
\text { required }\end{array}$ \\
\hline Lung & $\begin{array}{c}\text { DLCO }>80 \% \\
\text { FVC }>80 \% \\
\text { No fibrosis on } \\
\text { radiograph SPAP } \\
>30 \mathrm{mhg}\end{array}$ & $\begin{array}{c}\text { DLCO } 70-80 \% \text { FVC } \\
=70-80 \% \\
\text { Basilar rales fibrosis } \\
\text { on radiograph } \\
\text { SPAP }=35-49 \mathrm{mhg}\end{array}$ & $\begin{array}{c}\text { DLCO50-69\% FVC } \\
=50-69 \% \text { SPAP }= \\
50-69 \mathrm{mhg}\end{array}$ & $\begin{array}{c}\mathrm{DLCO}<50 \% \mathrm{FVC}< \\
50 \% \mathrm{SPAP}>65 \mathrm{mhg}\end{array}$ & oxygen required \\
\hline Heart & $\begin{array}{l}\text { ECG normal } \\
\text { LVEF }>50 \%\end{array}$ & $\begin{array}{c}\text { EKG conduction } \\
\text { defect } \\
\text { LVEF }= \\
45-49 \%\end{array}$ & $\begin{array}{c}\mathrm{EKG}=\text { Arrhythmia } \\
\mathrm{LVEF}= \\
40-44 \%\end{array}$ & $\begin{array}{c}\mathrm{EKG}= \\
\text { Arrhythmia LVEF = } \\
30-40 \%\end{array}$ & CHF LVEF $<30 \%$ \\
\hline Kidy & $\begin{array}{l}\text { No history of } \\
\text { SRC with serum } \\
\text { creatinine }< \\
1.3 \mathrm{mg} / \mathrm{dl}\end{array}$ & $\begin{array}{c}\text { No history of SRC } \\
\text { with serumcr1.3- } \\
1.6 \mathrm{mg} / \mathrm{dL}\end{array}$ & $\begin{array}{l}\text { History of SRC with } \\
\text { serum } \mathrm{cr}=1.7-2.9 \mathrm{mg} / \mathrm{dL}\end{array}$ & $\begin{array}{l}\text { history of SRC with } \\
\text { serum } \mathrm{cr}=3>\mathrm{mg} / \mathrm{dL}\end{array}$ & $\begin{array}{c}\text { history of SRC with } \\
\text { serum } \mathrm{cr} \\
>5 \mathrm{mg} / \mathrm{dL} \text { or } \\
\text { dialysis required }\end{array}$ \\
\hline
\end{tabular}

$\mathrm{WT}=$ Weight $\mathrm{PCV}=$ packed cell volume (hematocrit) $\mathrm{Hb}=$ hemoglobin, $\mathrm{TSS}=$ total skin score, FTP $=$ fingertip to palm distance in flexion, $\mathrm{DLCO}=$ diffusing capacity for carbon monox$\mathrm{ide} \%$ predicted, $\mathrm{FVC}=$ forced vital capacity $\%$ predicted, SPAP =estimated pulmonary artery pressure by Doppler echo, $\mathrm{EKG}=$ electrocardiogram, LVEF $=$ Left ventricular Ejection Fraction

had positive stool antigens. The relative frequencies of severe and end-stage levels for all organs of the body in patients with $H$. pylori were significantly higher than those without $H$. pylori infection (table 2). The results of Spearman correlation analysis revealed that there was a significant and positive association between $H$. pylori stool antigen titer and the severity of involvement of all organs $(p<0.001)$ (table 3$)$. In the positive H.pylori group, the general symptoms were significantly more severe $(p=0.001)$. Peripheral vascular involvement was observed in the positive H.pylori group, but this complication was not reported in the negative H.pylori group. Skin, gastrointestinal tract, and lung were also damaged in H. pyloripositive group with significantly higher severity ( $p=$ $0 / 001$ ) (table 3). Heart involvement was not significant, and kidney function was normal in both groups of study.

\section{DISCUSSION}

It has been considerable data in the past decades on the role of primary stimulants, especially infections, in the development and exacerbation of SSc symptoms. Studies have confirmed that infectious and environmental factors can have roles as stimulants for immune SSc patients. System activity, leading to its dysfunction and exacerbation of the symptoms in $H$. pylori infection, has a relatively high prevalence in the Middle East and Iran. ${ }^{9}$ Almost half of the world population suffers from this infection, and it is recognized as the main cause of chronic gastritis with complications such as peptic ulcers, gastric adenocarcinoma, and lymphoma. The prevalence and incidence of this infection are decreasing in most developed countries. But in developing countries, it still has a high prevalence. ${ }^{10}$ Low socioeconomic conditions, health, and nutrition play a major role in $H$. pylori incidence and its states since childhood. In Iran, almost $90 \%$ of the adult population is infected with this bacillus, ${ }^{11}$ in 
Table 2: Comparison of the severity of organ involvement in two groups of patients with positive and negative Helicobacter pylori

\begin{tabular}{|c|c|c|c|c|c|c|c|}
\hline \multirow{2}{*}{ Organ System } & & Normal & Mild & Moderate & Severe & End Stage & \multirow{2}{*}{$p$ value } \\
\hline & & N (\%) & $\mathrm{N}(\%)$ & $\mathrm{N}(\%)$ & $\mathrm{N}(\%)$ & $\mathrm{N}(\%)$ & \\
\hline \multirow{2}{*}{ General } & Positive & $4(12.1)$ & $12(36.4)$ & $12(36.4)$ & $5(15.2)$ & $0(0)$ & \multirow{2}{*}{0.001} \\
\hline & Negative & $27(65.9)$ & $12(29.3)$ & $2(4.9)$ & $0(0)$ & $0(0)$ & \\
\hline \multirow{2}{*}{$\begin{array}{l}\text { Peripheral } \\
\text { vascular }\end{array}$} & Positive & $0(0)$ & $1(3)$ & $8(24.2)$ & $22(66.7)$ & $2(6.1)$ & \multirow{2}{*}{0.001} \\
\hline & Negative & $0(0)$ & $0(0)$ & 25 & $0(0)$ & $0(0)$ & \\
\hline \multirow{2}{*}{ Skin } & Positive & $0(0)$ & $0(0)$ & $7(21.2)$ & $24(72.7)$ & $2(6.1)$ & \multirow{2}{*}{0.001} \\
\hline & Negative & $0(0)$ & $5(12.2)$ & $21(51.2)$ & $15(36.6)$ & $0(0)$ & \\
\hline \multirow{2}{*}{ Joint/tendon } & Positive & $0(0)$ & $2(6.1)$ & $7(21.2)$ & $22(66.7)$ & $2(6.1)$ & \multirow{2}{*}{0.004} \\
\hline & Negative & $0(0)$ & $6(14.6)$ & $21(51.2)$ & $14(34.1)$ & $0(0)$ & \\
\hline \multirow{2}{*}{ Muscle } & Positive & $0(0)$ & $22(66.7)$ & $10(30.3)$ & $1(3)$ & $0(0)$ & \multirow{2}{*}{0.003} \\
\hline & Negative & $4(9.8)$ & $34(82.9)$ & $2(4.9)$ & $1(2.4)$ & $0(0)$ & \\
\hline \multirow[t]{2}{*}{ Gastro-intestinal } & Positive & $0(0)$ & $0(0)$ & $8(24.2)$ & $23(69.7)$ & $2(6.1)$ & \multirow{2}{*}{0.001} \\
\hline & Negative & $0(0)$ & $0(0)$ & $28(68.3)$ & $13(31.17)$ & $0(0)$ & \\
\hline \multirow{2}{*}{ Lung } & Positive & $4(12.1)$ & $7(21.2)$ & $9(27.3)$ & $13(39.4)$ & $0(0)$ & \multirow{2}{*}{0.001} \\
\hline & Negative & $23(56.1)$ & $7(17.1)$ & $10(24.4)$ & $1(2.4)$ & $0(0)$ & \\
\hline \multirow{2}{*}{ Heart } & Positive & $12(36.4)$ & $21(63.6)$ & $0(0)$ & $0(0)$ & $0(0)$ & \multirow{2}{*}{0.001} \\
\hline & Negative & $30(73.2)$ & $10(24.4)$ & $1(2.4)$ & $0(0)$ & $0(0)$ & \\
\hline \multirow{2}{*}{ Kidney } & Positive & $11(33.3)$ & $21(63.6)$ & $1(3)$ & $0(0)$ & $0(0)$ & \multirow{2}{*}{0.001} \\
\hline & Negative & $31(75.6)$ & $9(22)$ & $1(2.4)$ & $0(0)$ & $0(0)$ & \\
\hline
\end{tabular}

Table 3: The correlation between the amount of Helicobacter pylori antigen titer and organ involvement severity

\begin{tabular}{llcccccc}
\hline $\begin{array}{l}\text { Organ } \\
\text { System }\end{array}$ & Kidney & Heart & Lung & $\begin{array}{c}\text { Gastro- } \\
\text { intestinal } \\
\text { tract }\end{array}$ & Muscle & $\begin{array}{c}\text { Joint/ } \\
\text { Tendon }\end{array}$ & $\begin{array}{c}\text { Skin } \\
\text { Veripheral } \\
\text { Vascular } \\
\begin{array}{l}\text { Correlation } \\
\text { coefficient }\end{array}\end{array}$ \\
\hline
\end{tabular}

addition, its current prevalence is reported to be $82 \%$ in Jordan and $78.4 \%$ among industrial workers. In the countries neighboring Iran, such as Turkey, the United Arab Emirates, and Saudi Arabia, a high prevalence of about $70 \%$ has been reported. Therefore, H. pylorus is a common infection among the adult population in Iran. In order to treat this condition, early diagnosis and treatment for several weeks are required. ${ }^{12}$ Eradication of $H$. pylori has special algorithms that are applied based on the patient's condition. Studies have reported an association between H. pylori infection and autoimmune diseases such as scleroderma. ${ }^{13}$ Patients without $H$. pylori infection had acceptable levels of general and constitutional symptoms like weight loss and physical endurance. Raynaud's symptoms, peripheral vascular ischemia, arthralgia, dysphagia, and malabsorption symptoms ${ }^{14}$ were significantly less than those with positive $H$. pylori infection. Cardiopulmonary and renal involvement was not common. Muscle weakness was not significantly different between patients with and without $H$. pylori infection. In $H$. pylori-positive patients with SSC, skin fibrosis and total skin score were more diffuse and high, respectively. There was a strong and significant correlation between the quantitative antigen titer of $H$. pylori and the severity of organ involvement. Pulmonary dysfunction due to restrictive lung disease and pulmonary fibrosis with high pulmonary artery pressure were detected more in $H$. pylori-positive patients. Interestingly gastrointestinal and skin involvement with higher total skin score were less severe in the negative H. pylori group.

Regarding the above findings, it can be concluded that patients with scleroderma and $H$. pylori infection expe- 
rience greater disease severity. It is important to note that these patients had received cytotoxic drugs generally at the early stage of pulmonary involvement or the onset of severe involvement of other target organs. However, none of these patients had received long-term high-dose corticosteroids.

In the group with positive $H$. pylori infection, nine patients out of 33 patients $(27.3 \%)$ were receiving cyclophosphamide, and seven patients $(21.2 \%)$ were receiving mycophenolate. However, in the group with negative $H$. pylori infection, only four patients $(9.8 \%)$ were receiving cyclophosphamide, and four patients $(9.8 \%)$ were receiving mycophenolate. Therefore the average titer of $H$. pylori antigen titer in those receiving cytotoxic drugs was significantly higher than that in other patients $(p<$ $0.001)$. The titer of $H$. pylori stool antigen titer was higher in the patients receiving cyclophosphamide, but the difference between the two groups was not significant. Based on these findings, it can be concluded that patients with more severe disease receive cytotoxic drugs and also have organ involvement. In this group, the titer of H.pylori antigen is higher and these results of the current study is consistent with other studies.

Another reason is upon weakening of the immune system by using cytokine drugs; patients become more susceptible to infections including $H$. pylori. Since the detection of $H$. pylori infection in all scleroderma patients before receiving cytotoxic drugs has not been performed, the above-mentioned interpretation should be justified carefully. These two factors cannot be differentiated from each other. This study revealed that $H$. pylori titer in patients suffering from scleroderma correlates directly with the severity of organ involvement. However, longitudinal follow-up studies including standard eradication of $H$. pylori infection in these group of patients should be done in order to confirm the direct impact of this infection on the exacerbation of target organ involvement. Studies have shown that different mechanisms may lead to extra gastrointestinal manifestations of $H$. pylori infection. These mechanisms include molecular similarity, endothelial cell injury, super antigens, and microchimerism.

The molecular similarity is an established mechanism in gastric mucosal injury with $H$. pylori infection. As large volumes of pre-inflammatory elements are produced, including cytokines, eicosanoids, and acute-phase proteins, the injury may also be observed in different organs. Moreover, inflammatory responses can generate complex antigen-antibody or antibodies with certain cross-reaction, i.e., molecular similarity. This can happen in vascular endothelial injury observed in patients with scleroderma. ${ }^{15}$ In addition, severe endothelial injury can be the result of direct invasion of the bacillus to the vessel wall, leading to vasculitis or even inflammatory reaction in response to this invasion. ${ }^{16}$ This may happen in endothelial cell of the lung capillary, which leads to significant damage in patients with high $H$. pylori antibody titer. Microbial super antigens can stimulate T-cells and subsequently lead to B-cell reaction and binding to MHC II on the super antigen surface where, in turn, the bindings eventually stimulate T-cell helper activity. ${ }^{17}$ Microchimerism is the gene and DNA transfers from one person or organism to another. Microchimerism has been reported in $82.9 \%$ of skin and peripheral blood samples from patients with scleroderma compared with $63.9 \%$ in the control group, ${ }^{18}$ The level of CD8 + and gamma/delta T-cells in the peripheral circulation is higher in the patients with SSc compared with the control group.

In individuals with T-cell microchimerism in circulation, the endothelial cells are stimulated by their products, similar to the situation of T-cells in graft-versus-host disease. H. pylori infection can be a stimulant of $\gamma / \delta$ (gamma-delta) T-cells, which is clearly observed in the skin of the patients with scleroderma. Exposure of $\gamma / \delta \mathrm{T}$ cells to this infectious agent changes the protector Th2 to cytotoxic Th1 and activates the inflammatory pathways. Moreover, $\gamma / \delta$ T-cells can contribute to the process of self-destruction caused by microchimerism. In addition, some gene polymorphisms can cause symptoms similar to scleroderma as a result of infectious agents. Hence, it can be concluded that the presence of $H$. pylori can stimulate endothelial injury leading to fibrosis and organ dysfunction.

\section{CONCLUSION}

The results of this study revealed a strong and significant direct correlation between the severity of organ involvement and $H$. pylori titer. The magnitude of the role of $H$. pylori infection has to be proved by a longitudinal study 
starting with standard eradication of $H$. pylori in the infected group since the diagnosis of the titer of antigen and the correlation between the $H$. pylori titer, and the severity of target organ damage should be evaluated regularly with specific intervals.

\section{ACKNOWLEDGMENTS}

We thank all those who helped us to prepare this work especially the Department of Rheumatology, Mashhad University of Medical Sciences, Iran.

\section{ETHICAL APPROVAL}

There is nothing to be declared.

\section{CONFLICT OF INTEREST}

None declared.

\section{Funding}

The Research Council of Mashhad University of Medical Sciences, Mashhad, Iran, is appreciated for financially supporting this study, grant number [No. 940474]

\section{REFERENCES}

1. Mottaghi P, Karimifar M, Salesi M, Karimzadeh H, Seyed Bonakdar Z, Ja'fari S. Parenchymal Lung Involvement in Patients with Systemic Sclerosis Admitted to Isfahan's Noor and Al-Zahra Hospitals. RJMS 2010;17:67-72.

2. Denton CP. Advances in pathogenesis and treatment of systemic sclerosis. Clin Med 2016;16:55-60. doi: 10.7861/clinmedicine.16-1-55.

3. Van Den Hoogen F, Khanna D, Fransen J, Johnson SR, Baron M, Tyndall A, Matucci-Cerinic M, Naden RP, Medsger Jr TA, Carreira PE, Riemekasten G. 2013 classification criteria for systemic sclerosis: an American College of Rheumatology/European League against Rheumatism collaborative initiative. Arthritis Rheum 2013;65:2737-47. doi: 10.1002/art.38098.

4. Schieir O, Thombs BD, Hudson M, Boivin JF, Steele R, Bernatsky S, Hanley J, Baron M, Canadian Scleroderma Research Group. Prevalence, severity, and clinical correlates of pain in patients with systemic sclerosis. Arthritis Care Res 2010;62:409-17. doi: 10.1002/acr.20108.

5. Varga J, Abraham D. Systemic sclerosis: a prototypic multisystem fibrotic disorder. J Clin Invest 2007; 117:55767. doi: $10.1172 / \mathrm{JCI} 31139$.

6. Smyk DS, Koutsoumpas AL, Mytilinaiou MG, Rigopoulou EI, Sakkas LI, Bogdanos DP. Helicobacter pylori and autoimmune disease: cause or bystander. World J Gastroenterol 2014;20:613-29. doi: 10.3748/wjg.v20.i3.613.
7. Radić M, Kaliterna DM, Bonacin D, Radić J, Fabijanić D. Eradication of Helicobacter pylori reduce disease activity and severity in systemic sclerosis. Ann Rheum Dis 2012;71:A29. doi: 10.1136/annrheumdis-2011-201232.8.

8. Geirsson ÁJ, Wollheim FA, Åkesson A. Disease severity of 100 patients with systemic sclerosis over a period of 14 years: using a modified Medsger scale. Ann Rheum Dis 2001;60:1117-22. doi: 10.1136/ard.60.12.1117.

9. Ferri C, Valentini G, Cozzi F, Sebastiani M, Michelassi C, La Montagna G, et al. Systemic sclerosis: demographic, clinical, and serologic features and survival in 1,012 Italian patients. Medicine 2002;81:139-53. doi: 10.1097/00005792-200203000-00004.

10. Randone SB, Guiducci S, Cerinic MM. Systemic sclerosis and infections. Autoimmun Rev 2008;8:36-40. doi: 10.1016/j.autrev.2008.07.022.

11. Lobo-Yeo A, Lamb JR. Superantigens as immunogens and tolerogens. Clin Exp Rheumatol 1993;11:S17-21.

12. Rak JM, Pagni PP, Tiev K, Allanore Y, Farge D, Harle $\mathrm{JR}$, et al. Male microchimerism and HLA compatibility in French women with sclerodema: a different profile in limited and diffuse subset. Rheumatology 2009;48:363-6. doi: 10.1093/rheumatology/ken505.

13. Hamamdzic D, Kasman LM, LeRoy EC. The role of infectious agents in the pathogenesis of systemic sclerosis. Curr Opin rheumatol 2002;14:694-8. doi: 10.1097/00002281-200211000-00011.

14. Sahebari M, Javanbakht A, Mirfeizi Z. The effect of statins in treatment of Raynaud's phenomenon in scleroderma: a case series. J Case Rep 2016;4:25-7.

15. Gilliam AC. Scleroderma. Dermatologic Immunity 2008;10:258-79. doi: 10.1159/000131502.

16. Kozarov E. Bacterial invasion of vascular cell types: vascular infectology and atherogenesis. Future cardiol 2012;8:123-38. doi: 10.2217/fca.11.75.

17. Radić M. Role of Helicobacter pylori infection in autoimmune systemic rheumatic diseases. World J Gastroenterol 2014;20:12839. doi: 10.3748/wjg.v20.i36.12839.

18. Kelly hurries ruddy, et al . Progressive systemic sclerosis , text book of rheumatology . $10^{\text {th }}$ edit, saunders , phiudelphila, $2017 ; 2: 1223-43$. 